\title{
Survival capability of Campylobacter upsaliensis under environmental stresses
}

\author{
Walid Elmonir ${ }^{1 \dagger}$, Torrung Vetchapitak ${ }^{2 \dagger}$, Tomoko Amano ${ }^{3}$, Takako Taniguchi ${ }^{2}$ and Naoaki Misawa ${ }^{2,3^{*}}$
}

\begin{abstract}
Objective: Campylobacter upsaliensis has been recognized as an emerging pathogen. However, little is known about its survival in the environment. To evaluate its survival capability, we estimated the reduction in viable counts of $C$. upsaliensis after aerobic exposure to starvation in phosphate-buffered saline (PBS), acidity ( $\mathrm{pH}=4.3$ ), high osmolarity $(4 \% \mathrm{NaCl})$, and dryness in wet pulp disks at different temperatures. Also, survival in dog feces and dog food at variable temperate was assessed.

Results: Campylobacter upsaliensis remained culturable under starvation for 4 days at $25^{\circ} \mathrm{C}$ and for 10 weeks at $4{ }^{\circ} \mathrm{C}$. C. upsaliensis was also recoverable after exposure to high osmolality for 9 days, dryness for 5 days, and acidity for 2 days, respectively. Similarly, C. upsaliensis survived in dog feces and dog food for several days at $25^{\circ} \mathrm{C}$ and weeks at $4^{\circ} \mathrm{C}$. The survival capability of the organism was dependent on the water content, and also temperature. Notably, the tested C. upsaliensis strain was less resilient under all tested conditions than a C. jejuni strain used as a control. The findings showed that C. upsaliensis is able to survive under various environmental stresses, suggesting that it could pose a potential threat to public health.
\end{abstract}

Keywords: Campylobacter upsaliensis, Environmental stress, Survival, Campylobacter jejuni, Dog food, Dog feces

\section{Introduction}

Campylobacter upsaliensis (Cups), the most common Campylobacter species found particularly in dogs, has been recognized as an emerging human pathogen [1]. The Cups infection is associated with a self-limiting diarrheal disease in most human cases; other serious conditions have also been reported, including bloody diarrhea, bacteremia, Guillain-Barré syndrome and hemolyticuremic syndrome [2, 3]. Epidemiological studies have indicated that not only indirect transmission such as foodborne infection but also direct contact with infected dogs poses a significant risk for Cups infection in humans [3]. Children are thought to be more vulnerable to this risk. In fact, a significant association between cases of the infection in the $\leq 5$-year age group and the presence of a puppy in the household has been demonstrated $[4,5]$.

Although Campylobacter jejuni $(\mathrm{Cj})$ requires microaerophilic conditions, this pathogen has acquired the ability to adapt to severe environmental conditions to maintain its life cycle [6]. However, little is known about the survival capabilities of Cups in the environment.

The present study was performed to evaluate the survival of Cups under various environmental stresses. We examined the stress responses of Cups to starvation, dryness, acidity, and osmolality in an aerobic atmosphere at $4{ }^{\circ} \mathrm{C}$ and $25^{\circ} \mathrm{C}$. We also examined its survival in dog feces and dog food at both ambient temperatures.

\footnotetext{
*Correspondence: a0d901u@cc.miyazaki-u.ac.jp

tWalid Elmonir and Torrung Vetchapitak contributed equally as first

author

${ }^{2}$ Center for Animal Disease Control, University of Miyazaki, 1-1

Gakuenkibanadai-nishi, Miyazaki 889-2192, Japan

Full list of author information is available at the end of the article
}

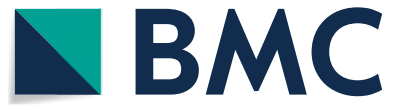

(c) The Author(s) 2022. Open Access This article is licensed under a Creative Commons Attribution 4.0 International License, which permits use, sharing, adaptation, distribution and reproduction in any medium or format, as long as you give appropriate credit to the original author(s) and the source, provide a link to the Creative Commons licence, and indicate if changes were made. The images or other third party material in this article are included in the article's Creative Commons licence, unless indicated otherwise in a credit line to the material. If material is not included in the article's Creative Commons licence and your intended use is not permitted by statutory regulation or exceeds the permitted use, you will need to obtain permission directly from the copyright holder. To view a copy of this licence, visit http://creativecommons.org/licenses/by/4.0/. The Creative Commons Public Domain Dedication waiver (http://creativeco mmons.org/publicdomain/zero/1.0/) applies to the data made available in this article, unless otherwise stated in a credit line to the data. 


\section{Main text}

\section{Materials and methods}

Bacterial strains

Cups LMG8850 was obtained from the Belgian Coordinated Collections of Micro-organisms (BCCM), Belgium. A human clinical strain, Cj 81-176, was used as a control [7]. Both strains were grown on blood agar No. 2 (Kanto Kagaku, Tokyo, Japan) containing 5\% defibrinated horse blood (Nippon Biotest Laboratories, Tokyo, Japan) at $37{ }^{\circ} \mathrm{C}$ for $48 \mathrm{~h}$ under microaerobic conditions $\left(75 \% \mathrm{~N}_{2}, 10 \% \mathrm{CO}_{2}, 5 \% \mathrm{H}_{2}\right.$, and $\left.10 \% \mathrm{O}_{2}\right)$.

\section{Survival of Campylobacter species exposed to starvation, dryness, acidity and high osmolality}

Survival to starvation The 48-h cultivated Cups and Cj cells on blood agar plates were harvested in $10 \mathrm{mM}$ phosphate-buffered saline (PBS, pH 7.2) and the optical density at $550 \mathrm{~nm}\left(\mathrm{OD}_{550}\right)$ was adjusted to 0.1 , representing $8 \log _{10}$ colony-forming unit (CFU)/ml. Aliquots of bacterial suspension $(1 \mathrm{ml})$ were dispensed into glass tubes and covered with an aluminum cap. They were cultured aerobically in incubators at $25^{\circ} \mathrm{C}$ or $4{ }^{\circ} \mathrm{C}$. After predetermined incubation periods, the number of CFU in the PBS was measured by direct plating on blood agar.

Survival to dryness Aliquots of $50 \mu$ l of bacterial suspension $\left(0.1 \mathrm{OD}_{550}\right)$ were dropped onto sterilized pulp disks $10 \mathrm{~mm}$ in diameter used for detection of antimicrobial agents (Toyo Roshi, Tokyo, Japan). These were placed in covered petri dishes $90 \mathrm{~mm}$ in diameter (Iwaki, Tokyo, Japan) and incubated aerobically at $25^{\circ} \mathrm{C}$ or $4{ }^{\circ} \mathrm{C}$. After predetermined incubation periods, the weight variation of the pulp disks was measured, and then the number of CFU in the disk was determined by direct plating on blood agar.

Survival to acidic or high osmolality stress was conducted as described elsewhere [7], with some modifications. In brief, the $\mathrm{pH}$ of Brucella broth (Beckton Dickinson, MD, USA) was adjusted to 4.3 by adding hydrochloric acid $(\mathrm{HCl})$ (Nacalai Tesque, Kyoto, Japan) and used as a form of acidic stress. For the high osmolality stress test, $3.5 \mathrm{~g}$ of sodium chloride $(\mathrm{NaCl})$ (Nacalai Tesque) was added to $100 \mathrm{ml}$ of Brucella broth resulting in a final concentration of $4 \% \mathrm{NaCl}$, since Brucella broth already contains $0.5 \% \mathrm{NaCl}$. The 48-h cultivated Campylobacter spp. were inoculated in the modified Brucella broths, and the $\mathrm{OD}_{550}$ of both inoculated broths was adjusted to 0.1 . The bacterial counts were conducted as described above.
Bacterial survival in dog feces, and dog food artificially spiked with Campylobacter spp.

Survival in dog feces Stool material was collected from a healthy adult dog and confirmed to be Campylobacter spp.-negative using enrichment followed by direct plating culture [8]. This fecal material (20 g) was then inoculated by mixing $20 \mathrm{ml}$ of $8 \log _{10} \mathrm{CFU} / \mathrm{ml} \mathrm{Cups}$ and $\mathrm{Cj}$ in a sterile stomacher bag (Central Scientific Commerce Inc., Tokyo, Japan), and homogenized for $2 \mathrm{~min}$. Then, 1-g aliquots of feces were placed in covered petri dishes $35 \mathrm{~mm}$ in diameter (Iwaki) and incubated aerobically at $25{ }^{\circ} \mathrm{C}$ or $4{ }^{\circ} \mathrm{C}$. After predetermined incubation periods, the number of culturable cells in the fecal sample was measured by direct plating on Skirrow selective agar plates (Kanto Kagaku) after 4 days of incubation at $37{ }^{\circ} \mathrm{C}$ under microaerobic conditions as described above.

Survival in dog food A wet-type dog food (water content $80 \%$ ) and a dry-type dog food (water content $10 \%$ ) whose major ingredients were chicken meat and beef were purchased from a pet shop. Each food (20 g) was inoculated with $20 \mathrm{ml}$ of $8 \log _{10} \mathrm{CFU} / \mathrm{ml}$ bacterial cells in a sterile stomacher bag. The wet-type food was then homogenized for $2 \mathrm{~min}$ but the dry type was suspended for $10 \mathrm{~min}$ before homogenization. The incubation, the food weight measurement, and the CFU count were conducted as described above.

\section{Statistical analysis}

Each experiment was repeated three times and mean microbial counts were converted to $\log _{10} \mathrm{CFU} / \mathrm{g}$. Pearson's correlation coefficient $(\mathrm{R})$ was used to examine the relation between Cups and $\mathrm{Cj}$ counts and the respective weights of feces, food and wet pulps. Statistical significance was defined as $P \leq 0.05$.

\section{Results and discussion \\ Survival of campylobacters in PBS under an aerobic atmosphere}

The viable count of Cups fell below the detection limit after 5 days of incubation at $25{ }^{\circ} \mathrm{C}$, while $\mathrm{Cj}$ did so at 6 days (Fig. 1A). In contrast, the culturabilities after incubation at $4{ }^{\circ} \mathrm{C}$ extended until 9 weeks for Cups and until 10 weeks for $\mathrm{Cj}$ (Fig. 1B). An environment contaminated with Campylobacter, particularly water, can pose a possible risk for transmission to animals and humans [9] and the present study showed that Cups retained its culturability in PBS under starvation stress and an aerobic atmosphere for several weeks at $4{ }^{\circ} \mathrm{C}$. Indeed, in a case study of Cups infection in a hiker, 
(A)

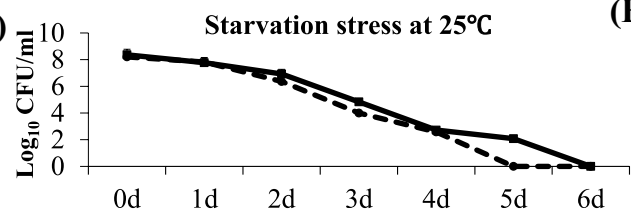

(C)

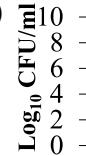

Acidic stress at $4^{\circ} \mathrm{C}$

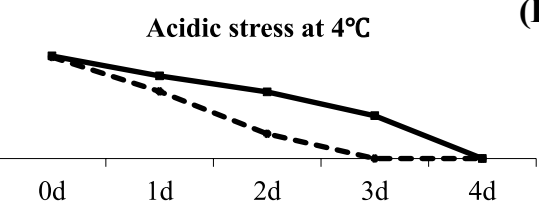

(B)

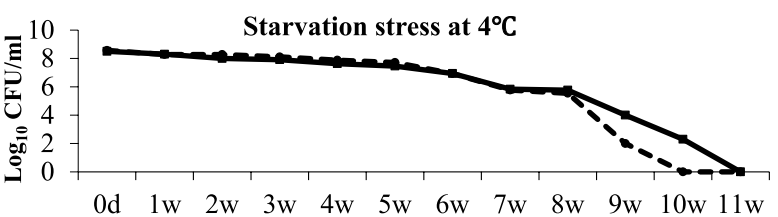

(D)

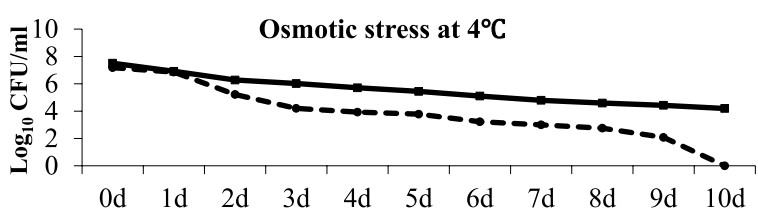

(E) $\left.\begin{array}{r}10 \\ 8\end{array}\right] \quad$ Dryness stress at $4^{\circ} \mathrm{C}$

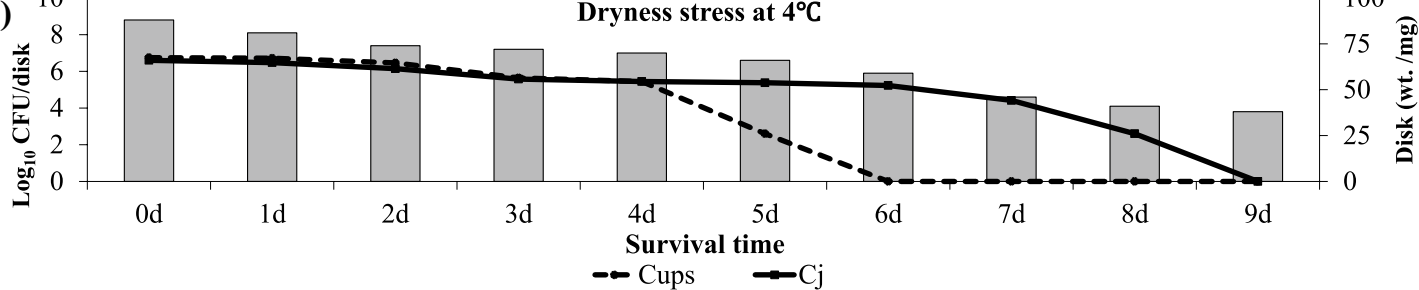

Fig. 1 Survival of Campylobacter spp. exposed to starvation, dryness, acidity and osmolarity stress in aerobic atmosphere at different temperatures. A Effect of starvation on the survival of C. upsaliensis (Cups) and C. jejuni $(\mathrm{Cj})$ at $25^{\circ} \mathrm{C}$. B Effect of starvation on the survival of Cups and Cj at $4{ }^{\circ} \mathrm{C}$. $\mathbf{C}$ Effect of acidic stress on the survival of Cups and $\mathrm{Cj}$ at $4^{\circ} \mathrm{C}$. D Effect of osmotic stress on the survival of Cups and $\mathrm{Cj}$ at $4{ }^{\circ} \mathrm{C}$. $\mathbf{E}$ Effect of dryness stress on the survival of Cups and $\mathrm{Cj}$ at $4^{\circ} \mathrm{C}$. Survival capability was determined in terms of $\log _{10}$ culture-forming units (CFU). Values are the mean of three independent experiments

the source of infection was suspected to be drinking of unsterilized spring water [10].

\section{Survival of campylobacters under acidity, osmotic stress, and dryness}

Cups showed a marked decline in the viable counts $\left(\sim 6 \log _{10}\right)$ after 2 days of incubation in $4.3 \mathrm{pH}$ medium at $4{ }^{\circ} \mathrm{C}$ and was not detectable by 3 days. $\mathrm{Cj}$ was less severely affected and was culturable until 3 days of incubation (Fig. 1C). Cj was reported to grow well at $\mathrm{pH}$ 6.5-7.5, but its survival rapidly diminished at acidic $\mathrm{pH}$ [11]. The high sensitivity of Cups to acidity, suggesting lower survival under gastric acidity, may account for the lower incidence of Cups infection in humans. However, it has been suggested that ingestion of pathogenic Campylobacter with water [9] or certain foods [12], which act as buffers, may increase their survival in extremely acid conditions.

For osmolality stress, Cups survived for 9 days in highosmolarity broth medium $(4 \% \mathrm{NaCl})$ at $4{ }^{\circ} \mathrm{C}$, but was more vulnerable than $\mathrm{Cj}$ (Fig. 1D). Under the same incubation conditions, $\mathrm{Cj}$ was culturable for 10 days with a $\sim 3 \log _{10}$ decline from the initial count. This agreed with a previous study that demonstrated a decrease of about $3 \log _{10}$ in the $\mathrm{Cj}$ count within 14 days at $4{ }^{\circ} \mathrm{C}$ in the presence of $4.5 \% \mathrm{NaCl}$ [13].

For dryness stress, the counts of both species declined simultaneously with continuous loss of moisture content in the inoculated pulp disks at $4{ }^{\circ} \mathrm{C}$. Cups and $\mathrm{Cj}$ showed high sensitivity to dryness, and their viable counts fell below the detection limit by 6 and 9 days at $4{ }^{\circ} \mathrm{C}$, respectively (Fig. 1E); this highlighted the importance of moisture content for survival of both species in the environment. This is in accord with previous reports that demonstrated long survival of $\mathrm{Cj}$ for more than 80 days in filter-sterilized stream water at low temperature [14] and a rapid decline in numbers under dry conditions [15]. Notably, both species failed to survive dryness, acidity and high osmolarity at $25^{\circ} \mathrm{C}$ for $24 \mathrm{~h}$, which highlight the key role of ambient temperature in survival of Campylobacter spp. to stresses in low nutrient environment.

\section{Survival of Campylobacter species in dog feces}

Cups survived in dog feces for about 3 days at $25{ }^{\circ} \mathrm{C}$ and for a longer time at low temperature (Fig. 2A, B). A marked difference in the survival of Cups relative to $\mathrm{C}$ was notable at the 1 st week at $4{ }^{\circ} \mathrm{C}\left(\sim 3 \log _{10}\right)$, suggesting that temperature may not be the sole factor influencing the survival of Cups in dog feces. Notably, the moisture content of the feces affected the survival of both of the Campylobacter spp. examined. A decline in the moisture content of dog feces was correlated with the decline in survival of both Campylobacter spp. $\left(\mathrm{R}=0.8, P^{<} 0.01\right)$. The moisture content of animal feces has also been reported to affect the survival of Campylobacter spp. as 


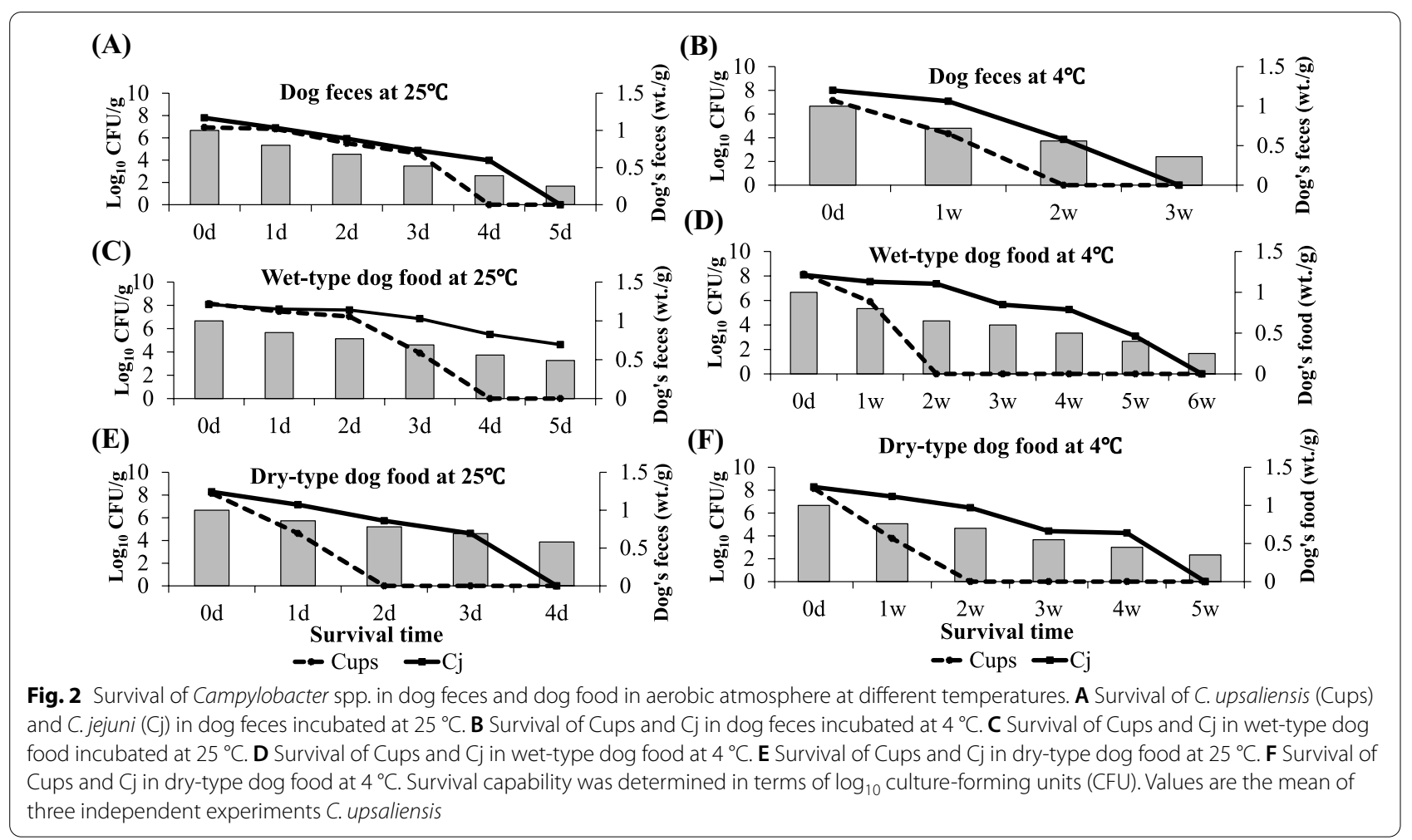

well as that of other enteric bacteria such as Salmonella and Escherichia coli [16]. Previous reports have suggested that $\mathrm{Cj}$ survives for a variable time in cattle and poultry feces $[17,18]$. However, there have been no available data on survival of Campylobacter spp. in dog feces.

\section{Survival of Campylobacter species in dog food}

In this study, we examined the survival of Cups and $\mathrm{Cj}$ in wet- and dry-type dog foods incubated aerobically at $25{ }^{\circ} \mathrm{C}$ and $4{ }^{\circ} \mathrm{C}$. The viable count of Cups fell below the detection limit at 4 days after incubation at $25{ }^{\circ} \mathrm{C}$ (Fig. 2C) and at 2 weeks at $4{ }^{\circ} \mathrm{C}$ (Fig. 2D), while $\mathrm{Cj}$ was still culturable after 5 days at $25^{\circ} \mathrm{C}$ (Fig. 2C) and after 5 weeks at $4{ }^{\circ} \mathrm{C}$ (Fig. 2D). The culturability of both Campylobacter spp. was shorter in the dried food than in the wet food (Fig. 2E, F). The survival of Campylobacter spp. in dog food (Fig. 2C-F), was correlated with its moisture content at both temperatures $(\mathrm{R}=0.7-0.9, P \leq 0.01)$. Many factors affect the survival of microorganisms in foods, including moisture, osmolarity and acidity [19]. The relatively short survival of Cups in dog food, especially dry-type food, may be attributed to sensitivity to these stressors. The present data on the survival of Cups in dog feces and dog food suggest an infectious source of transmission to other animals and to humans, although epidemiological data for dogs have been unavailable up to now.
Campylobacter spp. survive in the environment through mechanisms such as aerotolerance, biofilm formation, adaptive tolerance responses and transformation to a viable but nonculturable (VBNC) [6]. In all of the present experiments, the culturability of Cups was lower than that of $\mathrm{Cj}$ to a varying degree. This inter-species difference in survival tolerance to stress has been reported before [20]. One possible explanation for this is the variation in catalase production by these organisms. It is considered that catalase produced by Campylobacter spp. protects them from damage caused by oxygen radicals [21]. As Cups was originally described as a catalase-negative or weakly positive organism [22], this may account for its lower survival capability in comparison to $\mathrm{Cj}$ under aerobic conditions.

The risk arising through continuous and daily contact with household dogs, especially for children, has been emphasized. For prevention of new human cases, there is an urgent need for better public awareness and improved detection techniques for Cups. The present study provides the first information on the survival of Cups in the rearing environment of dogs, which may help to clarify possible routes of infection and prevent transmission of this pathogen to humans. 


\section{Limitations}

This study has some limitations. We have investigated only one type strain as a representative Campylobacter spp. and only two temperatures as an initial proof of concept. Furthermore, it is suggested that the phenotypic differences may be attributed to the high genetic diversity among Campylobacter spp. Therefore, the differences in survival patterns between Cups and $\mathrm{Cj}$ may be reflected in part by interspecies differences in stress response genes. Although the whole genomes of some Cups strains have been determined, the key genes related to the survival strategies of $\mathrm{Cj}$ have not yet been fully examined. While this study limited our ability to assume causality, findings may inform the direction of future research to understand the survival abilities of campylobacters under environmental stresses.

\section{Abbreviations}

Cups: Campylobacter upsaliensis; Cj: Campylobacter jejuni; BCCM: Belgian Coordinated Collections of Micro-organisms; PBS: Phosphate-buffered saline; OD: Optical density; CFU: Colony-forming-unit; $\mathrm{HCl}$ : Hydrochloric acid; $\mathrm{NaCl}$ : Sodium chloride; VBNC: Viable but nonculturable.

\section{Acknowledgements}

Not applicable.

\section{Authors' contributions}

WE designed and performed the experiments and wrote an original draft of the manuscript; TV analyzed the experimental data, edited and proofread the manuscript; TA and TT supported microbiological experiments; NM conceptualized and designed the study and revised the manuscript. All authors read and approved the final manuscript.

\section{Funding}

This work was supported by the grant (Grant No. JPMJSA1908) from Japan Science and Technology Agency (JST) for Science and Technology Research Partnership for Sustainable Development (SATREPS).

\section{Availability of data and materials}

The datasets used and/or analysed during the current study available from the corresponding author on reasonable request during the current study.

\section{Declarations}

Ethics approval and consent to participate Not applicable.

\section{Consent for publication}

Not applicable.

\section{Competing interests}

The authors declare that they have no competing interests.

\begin{abstract}
Author details
${ }^{1}$ Hygiene and Preventive Medicine (Zoonoses) Department, Faculty of Veterinary Medicine, Kafrelsheikh University, Kafrelsheikh 33511, Egypt. ${ }^{2}$ Center for Animal Disease Control, University of Miyazaki, 1-1 Gakuenkibanadai-nishi, Miyazaki 889-2192, Japan. ' ${ }^{3}$ Laboratory of Veterinary Public Health, Department of Veterinary Medical Science, Faculty of Agriculture, University of Miyazaki, 1-1 Gakuenkibanadai-nishi, Miyazaki 889-2192, Japan.
\end{abstract}

Received: 10 October 2021 Accepted: 25 January 2022

Published online: 14 February 2022
References

1. Procter T, Pearl D, Finley R, Leonard E, Janecko N, Reid-Smith R, Weese J, Peregrine A, Sargeant J. A cross-sectional study examining Campylobacter and other zoonotic enteric pathogens in dogs that frequent dog parks in three cities in South-Western Ontario and risk factors for shedding of Campylobacter spp. Zoonoses Public Health. 2014;61:208-18.

2. Goossens H, Vlaes L, DeBoeck M, Pot B, Kersters K, Levy J, De Mol P, Butzler J, VanDamme P. Is, "Campylobacter upsaliensis" an unrecognised cause of human disease? Lancet. 1990;335:584-6.

3. Bourke B, Chan VL, Sherman P. Campylobacter upsaliensis: waiting in the wings. Clin Microbiol Rev. 1998;11:440-9.

4. Hald B, Madsen M. Healthy puppies and kittens as carriers of Campylobacter spp. with special reference to Campylobacter upsaliensis. J Clin Microbiol. 1995;35:3351-2

5. Same RG, Tamma PD. Campylobacter infections in children. Pediatr Rev. 2018;39:533-41.

6. Vetchapitak T, Misawa N. Current status of Campylobacter food poisoning in Japan. Food Saf. 2019;7:61-73.

7. Jackson N, Davis B, Tirado S, Duggal M, van Frankenhuyzen J, Deaville D, Wijesinghe M, Tessaro M, Trevors J. Survival mechanisms and culturability of Campylobacter jejuni under stress conditions. Anton Leeuwenhoek Int J G. 2009;96:377-94

8. Ugarte-Ruiz M, Gómez-Barrero S, Porrero M, Álvarez J, García M, Comerón M, Wassenaar T, Domínguez L. Evaluation of four protocols for the detection and isolation of thermophilic Campylobacter from different matrices. J Appl Microbiol. 2012;113:200-8.

9. Koenraad PMFJ, Rombouts FM, Notermans SHW. Epidemiological aspects of thermophilic Campylobacter in water-related environments: a review. Water Environ Res. 1997:69:52-63.

10. Couturier B, Hale D, Couturier M. Association of Campylobacter upsaliensis with persistent bloody diarrhea. J Clin Microbiol. 2012:50:3792-4.

11. Chaveerach $P$, ter Huurne A, Lipman L, van Knapen F. Survival and resuscitation of ten strains of Campylobacter jejuni and Campylobacter coli under acid conditions. Appl Environ Microbiol. 2003;69:711-4.

12. Waterman S, Small P. Acid-sensitive enteric pathogens are protected from killing under extremely acidic conditions of $\mathrm{pH} 2.5$ when they are inoculated onto certain solid food sources. Appl Environ Microbiol. 1998;64:3882-6.

13. Doyle MP, Roman DJ. Response of Campylobacter jejuni to sodium chloride. Appl Environ Microbiol. 1982;43:561-5.

14. Chynoweth R, Hudson J, Thom K. Aerobic growth and survival of Campylobacter jejuni in food and stream water. Lett Appl Microbiol. 1998:27:341-4.

15. Murphy C, Carroll C, Jordan KN. Environmental survival mechanisms of the foodborne pathogen Campylobacter jejuni. J Appl Microbiol. 2006;100:623-32.

16. Moriarty E, Mackenzie M, Karki N, Sinton L. Survival of Escherichia coli, Enterococci, and Campylobacter spp. in sheep feces on pastures. Appl Environ Microbiol. 2011;77:1797-803.

17. Gilpin B, Robson B, Scholes P, Nourozi F, Sinton L. Survival of Campylobacter spp. in bovine faeces on pasture. Lett Appl Microbiol. 2009;48:162-6.

18. Ahmed M, Schulz J, Hartung J. Survival of Campylobacter jejuni in naturally and artificially contaminated laying hen feces. Poult Sci. 2013;92:364-9.

19. Beales N. Adaptation of microorganisms to cold temperatures, weak acid preservatives, low pH, and osmotic stress: a review. Compr Rev Food Sci Food Saf. 2004:3:1-20.

20. Korhonen L, Martikainen J. Comparison of the survival of Campylobacter jejuni and Campylobacter coli in culturable form in surface water. Can J Microbiol. 1991;37:530-3.

21. Day WA, Sajecki JL, Pitts TM, Joens LA. Role of catalase in Campylobacter jejuni intracellular survival. Infect Immun. 2000;68:6337-45.

22. Patton C, Shaffer N, Edmonds P, Barrett T, Lambert M, Baker C, Perlman D, Brenner D. Human disease associated with "Campylobacter upsaliensis" (catalase-negative or weakly positive Campylobacter species) in the United States. J Clin Microbiol. 2014;27:66-73.

\section{Publisher's Note}

Springer Nature remains neutral with regard to jurisdictional claims in published maps and institutional affiliations. 